No 4078

Studia nad Autorytaryzmem i Totalitaryzmem 43, nr 4 Wrocław 2021

https://doi.org/10.19195/2300-7249.43.4.5

\author{
ANNA ĆWIĄKAŁA-MAŁYS \\ ORCID: 0000-0001-9812-2118 \\ Uniwersytet Wrocławski \\ anna.cwiakala-malys@uwr.edu.pl
}

\author{
MAŁGORZATA DURBAJŁO-MROWIEC \\ ORCID: 0000-0003-0977-0960 \\ Uniwersytet Wrocławski \\ malgorzata.durbajlo-mrowiec@uwr.edu.pl
}

\title{
Koncepcja efektywności oceny przedsiębiorstw Polskiej Rzeczypospolitej Ludowej i jej ewolucja
}

Slowa kluczowe: efektywność przedsiębiorstwa, finanse, rachunek kosztów, radzieckie wzorce.

\author{
THE CONCEPT OF EFFICIENCY EVALUATION OF ENTERPRISES \\ OF THE POLISH PEOPLE'S REPUBLIC AND ITS EVOLUTION
}

\begin{abstract}
After the Second World War, in the time of totalitarian leadership, economic and inter-company settlement rules were implemented for the management of the Polish economy and Polish enterprises. Their purpose was to control the use of resources and the implementation of plans as well as to increase the efficiency and rationality of management. The term efficiency was not used. The aim of the article is to investigate whether the internal economic settlement, an inherent part of which was cost accounting, had the features of efficiency accounting. The research was carried out by qualitative, comparative and praxeological methods. The chronological views of selected economists from the times of the Polish People's Republic presented here indicate their significant evolution. With the end of the socialist economy, economists were writing about maximizing profits and the profitability of enterprises remaining on inter-company settlement, about the efficiency of their activities and financial independence. Cost accounting was modified to resemble the normative cost accounting model that provided multi-sectional information for managing, including evaluation of efficiency. That is why a tool was used that was not connected with the centralized economy but was an example of modern solutions that were necessary in a totalitarian country for achieving the desired level of control over society.
\end{abstract}

Keywords: enterprise efficiency, finances, cost accounting, Soviet patterns. 


\section{Wprowadzenie}

Po II wojnie światowej, wraz z całkowitym podporządkowaniem Polski komunistycznemu systemowi, do zarządzania polską gospodarką wdrożono rozrachunek gospodarczy i wewnątrzzakładowy, którego koncepcje pochodziły z ZSRR, a ich dzieje sięgały 1929 roku$^{1}$. Rozrachunek gospodarczy był i pozostaje do dzisiaj kategorią trudną do zdefiniowania. Niewątpliwie był to swego rodzaju mechanizm ekonomiczny „włożony” w ramy gospodarki socjalistycznej oraz systemu nakazowo-rozdzielczego. Celem tego mechanizmu była kontrola wykorzystania zasobów i realizacji planów oraz zwiększenia wydajności, racjonalności gospodarowania. Należy zauważyć, że nie posługiwano się wówczas terminem „efektywność”.

Celem artykułu jest zatem zbadanie, czy wewnątrzzakładowy rozrachunek gospodarczy, którego immanentną częścią był rachunek kosztów, miał cechy rachunku efektywności.

Badania przeprowadzono metodami: jakościową, porównawczą i prakseologiczną.

\section{Rozrachunek gospodarczy jako metoda zarządzania}

Rozrachunek gospodarczy należał do istotnej problematyki ekonomicznej, prawnej oraz z zakresu organizacji i zarządzania w krajach socjalistycznych ${ }^{2}$. W ujęciu ekonomicznym o rozrachunku gospodarczym pisał między innymi O. Lange ${ }^{3}$. O rozrachunku pisano już w latach pięćdziesiątych. Poza Langem pisali o nim również na przykład J. Kronrod ${ }^{4}$, W. Diaczenko ${ }^{5}$, Z. Fedorowicz ${ }^{6}$, J. Wierzbicki ${ }^{7}$ oraz inni autorzy, których poglądy zostały przedstawione poniżej.

Rozrachunek gospodarczy był bardzo różnie definiowany. W opinii J. Wierzbickiego jest on powiązany z samodzielnością gospodarczą przedsiębiorstw państwowych ${ }^{8}$. Wierzbicki podkreślał, że rozrachunek gospodarczy był wiązany z ,działaniem prawa wartości”. Dyskutowano, czy rachunek gospodarczy jest obiek-

${ }^{1}$ R. Sochacka, Rozrachunek wewnątrzzaktadowy a rachunek kosztów w ZSRR, „Acta Universitatis Lodziensis. Folia Oeconomica" 1984, nr 41, s. 36.

2 Z. Mitura, W kwestii pojęcia rozrachunku gospodarczego, „Annales Universitatis Mariae Curie-Skłodowska. Sectio H. Oeconomia” 1988, nr 22.

3 O. Lange, Ekonomia polityczna, t. 1. Zagadnienia ogólne, Warszawa 1959, s. 92.

4 J. Kronrod, Podstawy rozrachunku gospodarczego, przeł. B. Wścieklica, Warszawa 1954, s. $15-38$.

5 W. Diaczenko, Obiektywne podstawy rozrachunku gospodarczego, „Finanse” 1956, nr 4, s. $96-107$.

6 Z. Fedorowicz, O prawie wartości i rozrachunku gospodarczym, Warszawa 1957, s. 148-202.

7 J. Wierzbicki, Podstawy samodzielności gospodarczej przedsiębiorstw państwowych, „,Ruch Prawniczy i Ekonomiczny" 1958, nr 3, s. 135-147.

8 Ibidem, s. 135-136. 
tywną kategorią ekonomiczną czy metodą zarządzania. Wierzbicki twierdził, że „istnieją [...] przedsiębiorstwa oparte na zasadzie rozrachunku gospodarczego, mimo braku bezspornego sformułowania tego pojęcia"". Z. Mitura wskazywał, że rozrachunek gospodarczy jest elementem socjalistycznej gospodarki i nie jest stosowany w gospodarce kapitalistycznej. Pełni funkcję społeczno-ekonomiczną i umożliwia „dążenie do maksymalnego zaspokojenia potrzeb społecznych drogą racjonalnego wykorzystania rozporządzalnych środków w skali gospodarki narodowej jako całości"10.

O. Lange wiązał rozrachunek gospodarczy z zasadą racjonalnego gospodarowania. Uważał, że w parametrycznym systemie zarządzania pozwala on osiągać maksymalne cele przy danym poziomie środków (zasada największej wydajności), a w systemie nieparametrycznym — zminimalizować zużycie środków przy danym stopniu realizacji celu (zasada oszczędności środków).

W obu systemach rozrachunek gospodarczy jest zarówno metodą zwiększania racjonalności gospodarowania, jak też metodą oceny i kontroli działalności jednostek gospodarczych. W zasadach jego stosowania tkwią bowiem zarówno warunki umożliwiające racjonalne gospodarowanie, stymulatory zachęcające do zwiększania racjonalności gospodarowania, jak też system ocen stopnia gospodarności ${ }^{11}$.

Według Langego „społeczno-gospodarcza racjonalność działalności gospodarczej" przedsiębiorstw powinna być podporządkowana celowi ogólnospołecznemu. Integrację i koordynację celów umożliwia planowanie gospodarcze ${ }^{12}$. J. Mujżel uzasadniał potrzebę decentralizacji zarządzania własnością państwową i wyodrębnienia pod względem technicznym i organizacyjnym zakładów oraz zapewnienia im pewnego zakresu samodzielności ekonomicznej w celu poprawy efektywności gospodarowania $^{13}$.

W wersji dynamicznego rozrachunku gospodarczego podkreślano, jakie znaczenie ma „wysokość nadwyżki dochodów nad wydatkami, czyli wysokość zysku i zasady jego podziału pomiędzy państwo, przedsiębiorstwo i załogę"14. W latach osiemdziesiątych przedstawiciele ekonomii socjalistycznej i prawa gospodarczego, na przykład J. Wiszniewski ${ }^{15}$, zastanawiali się, czy taki pomiar efektywności działalności oznacza samodzielność finansową przedsiębiorstw pozostających na rozrachunku gospodarczym (równoważenie dochodów z wydatkami), czy rentowność polegającą na maksymalizacji zysku, o której w ówczesnym prawodawstwie raczej nie wspominano.

\footnotetext{
${ }^{9}$ Ibidem, s. 136.

10 Z. Mitura, op. cit., s. 421.

11 O. Lange, op. cit., s. 148-150.

12 Ibidem.

13 J. Mujżel, Stosunki towarowe w gospodarce socjalistycznej, Warszawa 1963, s. 59.

14 Z. Mitura, op. cit., s. 423.

15 J. Wiszniewski, Prawo gospodarcze, Warszawa 1982, s. 58.
} 
W 1950 roku Rada Ministrów wydała uchwałę w sprawie zasad organizacji finansowej i systemu finansowego przedsiębiorstw państwowych objętych budżetem centralnym ${ }^{16}$, w której to uchwale wyodrębniła przedsiębiorstwa na rozrachunku gospodarczym. W § 11 określono zasady działania tych przedsiębiorstw, które:

a) korzystają w wykonaniu zadań wynikających z planów gospodarczych z pełnej operatywnej samodzielności,

b) wchodzą w wykonaniu tych zadań w stosunki umowne $\mathrm{z}$ innymi przedsiębiorstwami i organizacjami,

c) prowadzą pełną rachunkowość, sporządzając pełny samodzielny bilans i rachunek wyników,

d) posiadają samodzielne rachunki w banku finansującym ich działalność eksploatacyjną,

e) korzystają bezpośrednio ze środków planu inwestycyjnego,

f) rozliczają się bezpośrednio z budżetem państwa,

g) korzystają z innych uprawnień przewidzianych w przepisach szczegółowych.

W przedsiębiorstwach wielozakładowych przewidziano stosowanie wewnątrzzakładowego rozrachunku gospodarczego (wrg) w zakładach, w formie pełnej lub ograniczonej. Wskazano również potrzebę przechodzenia na wewnątrzzakładowy rozrachunek gospodarczy przez wydziały i oddziały zakładów lub przedsiębiorstw $(\S 12)$.

Podsumowanie organizacji rozrachunku gospodarczego ujęto na rysunku poniżej.

\begin{tabular}{|c|c|}
\hline Rachunek gospodarczy & Ministerstwo \\
\hline $\boldsymbol{\nabla}$ & Zjednoczenie \\
\hline Rozrachunek wewnętrzny zjednoczenia & Przedsiębiorstwo \\
\hline $\boldsymbol{\nabla}$ & \\
\hline Rozrachunek wewnątrzzakładowy & Zakłady, wydziały \\
\hline $\boldsymbol{\nabla}$ &
\end{tabular}

Rysunek 1. Organizacja rozrachunku gospodarczego

Źródło: opracowanie własne na podstawie: R. Sochacka, Rozrachunek wewnatrzzakładowy a rachunek kosztów w ZSRR, „Acta Universitatis Lodziensis. Folia Oeconomica” 1984, nr 41, s. 35.

16 Uchwała Rady Ministrów z 17 kwietnia 1950 roku w sprawie zasad organizacji finansowej i systemu finansowego przedsiębiorstw państwowych objętych budżetem centralnym (M.P. z 1950 r. Nr A-55, poz. 630). 


\section{Rachunek kosztów w wewnątrzzakładowym rozrachunku gospodarczym}

Zgodnie z wytycznymi do wewnątrzzakładowego rozrachunku gospodarczego podstawowym źródłem informacji systemu miał być rachunek kosztów. Za najbardziej pożądany uznano model rachunku kosztów charakteryzujący się możliwością dostarczania informacji do planowania pracy wewnętrznych podmiotów w przedsiębiorstwie i oceny pracy podmiotów oraz motywowania członków systemu wewnątrzzakładowego rozrachunku gospodarczego, a jednocześnie dostarczający informacji do podejmowania decyzji krótkoterminowych i długookresowych (zarządczy rachunek kosztów) i umożliwiający przygotowanie kosztów do sporządzania sprawozdań zewnętrznych (systematyczny rachunek kosztów) ${ }^{17}$. Koszty są bowiem jedyną kategorią ekonomiczną, którą mierząc u źródła, można określić dla wyodrębnionych w przedsiębiorstwie zakładów, wydziałów i innych obiektów odniesienia. Na początku lat sześćdziesiątych opublikowano w Polsce wiele prac naukowych o rachunku kosztów ${ }^{18}$. W literaturze radzieckiej i polskiej pisano o konieczności grupowania kosztów według miejsc powstawania, zwanych centrami kosztów. Centrum kosztów definiowano jako

wydzielone w wydziałach produkcji podstawowej (tzw. centrum produkcyjne), grupy stanowisk o jednakowych parametrach, grupy pracowników wykonujących jednakową pracę lub grupy operacji, w skrajnym przypadku centrami kosztów może być jedno stanowisko, jeden pracownik, jedna operacja ${ }^{19}$.

Przewidziano również tak zwane centra obsługi świadczące usługi pomocnicze, takie jak remonty i konserwacje, oraz centra nominalne, do których należało przypisywać koszty ogólnego przeznaczenia, to jest koszty administracji i zarządzania, straty na brakach, koszty postojów, koszty nieprodukcyjne. Centra kosztów miały być wyodrębniane zgodnie ze strukturą organizacyjną przedsiębiorstw i miały służyć wewnętrznej kontroli kosztów wytworzenia. Zastrzegano, że centra kontroli kosztów nie są jednoznaczne z centrami odpowiedzialności za poziom kosztów. W poniższej tabeli przedstawiono strukturę organizacyjną miejsc powstawania kosztów i podmiotów wewnątrzzakładowego rozrachunku gospodarczego w przykładowym polskim przedsiębiorstwie produkcyjnym.

17 R. Sochacka, Rachunkowość w warunkach rozrachunku gospodarczego, praca doktorska, Łódź 1985, s. 167.

18 E. Nowak, Zarządzanie kosztami z perspektywy historycznej. Początki koncepcji w ośrodku wrocławskim, „Zeszyty Naukowe Politechniki Częstochowskiej. Zarządzanie” 2018, nr 30, s. 208.

19 A.D. Sheremiyet, K. Goli, Tioriya i praktika istisleniya sebestoimosti VSSR i KDR, Moskva 1977, s. 25. 
Tabela 1. Struktura podmiotów wewnątrzzakładowego rozrachunku gospodarczego a struktura organizacyjna i struktura miejsc powstawania kosztów w hutnictwie

\begin{tabular}{|l|l|l|}
\hline \multicolumn{1}{|c|}{ Struktura organizacyjna } & \multicolumn{1}{|c|}{$\begin{array}{c}\text { Struktura miejsc } \\
\text { powstawania kosztów }\end{array}$} & \multicolumn{1}{|c|}{$\begin{array}{c}\text { Struktura podmiotów } \\
\text { wewnątrzzakładowego } \\
\text { rozrachunku gospodarczego }\end{array}$} \\
\hline $\begin{array}{l}\text { wydział W1: } \\
\text { - zespół topielny } \\
\text { zespół topielny MS }\end{array}$ & wydział W1 & wydział W1 \\
\hline wydział W2 & wydział W2 & wydział W2 \\
\hline $\begin{array}{l}\text { wydział W3 } \\
\text { oddział W3/R }\end{array}$ & wydział W3 & $\begin{array}{l}\text { wydział W2: } \\
\text { - oddział W3/R }\end{array}$ \\
\hline $\begin{array}{l}\text { wydział W4 } \\
\text { oddział W5/C: } \\
\text { - piec topielny K } \\
\text { oddział W5/B: } \\
\text { - piec topielny T } \\
\text { - piec topielny B } \\
\text { - piece topielne RiS } \\
\text { - linia technologiczna SNBP } \\
\text { oddział W5/P }\end{array}$ & wydział W4 & wydział W4 \\
\hline
\end{tabular}

Źródło: opracowanie własne.

W rachunku kosztów prowadzonym w przykładowym przedsiębiorstwie gromadzone koszty tylko częściowo były wykorzystywane w wewnątrzzakładowym rozrachunku gospodarczym, a mianowicie:

— koszty materiałów bezpośrednich i wydziałowy koszt przerobu,

— koszty jednostkowe,

— koszty przerobu z wyodrębnionymi pozycjami analitycznymi.

Koszty zużycia materiałów i koszty przerobu wykorzystywano w analizie efektywności zrealizowanych zadań. Koszt jednostkowy był podstawą tworzenia cenników, a na podstawie kosztów przerobu ustalano preliminarze tych kosztów ${ }^{20}$.

W okresie stosowania wewnątrzzakładowego rozrachunku gospodarczego opracowano model rachunku kosztów apriorycznych, w którym wzorce kosztów budowano na bazie norm techniczno-technologicznych. Był to tak zwany rachunek kosztów normatywnych. Twórcą modelu był W. Malc. Cechą charakterystyczną rachunku kosztów normatywnych jest rozdzielcza forma prezentacji informacji o kosztach. To pozwala bezpośrednio wykorzystać tę kategorię ekonomiczną w zarządzaniu przedsiębiorstwem i jego podmiotami wewnętrznymi,

${ }^{20}$ Uchwała Rady Ministrów w sprawie zasad organizacji finansowej i systemu finansowego przedsiębiorstw państwowych objętych budżetem centralnym nakładała na przedsiębiorstwa, które zostały zobowiązane do działania zgodnie $\mathrm{z}$ wewnątrzzakładowym rozrachunkiem gospodarczym, obowiązek sporządzania preliminarzy kosztów utrzymania zakładów i ustalania cen metodą kosztową. 
w tym w kontrolowaniu realizacji produkcji, osiąganej wydajności, racjonalności wykorzystania zasobów oraz w ocenie efektywności działań.

W modelu tym koszty faktyczne $\left(\mathrm{K}_{\mathrm{f}}\right)$ w przekroju rodzajów, miejsc powstawania, nośników kosztów w rozwiniętej formule ujmuje się (również w systemie ewidencyjnym) i prezentuje $\mathrm{w}$ formie ${ }^{21}$ :

$$
\mathrm{K}_{\mathrm{f}}=\mathrm{K}_{\mathrm{a}} \pm \mathrm{R}_{\mathrm{s}} \pm \mathrm{R}_{\mathrm{n}}
$$

gdzie: $\mathrm{K}_{\mathrm{a}}$ - koszty ustalone z góry (a priori),

$\mathrm{R}_{\mathrm{S}}$ - różnice typu sprostowania (odchylenia $\mathrm{z}$ tytułu zmiany norm),

$\mathrm{R}_{\mathrm{n}}$ — różnice typu niedotrzymania (odchylenia kosztów faktycznych od standardowych).

Rozliczenie kosztów produkcji przebiega zaś w wariancie rozliczeniowym lub dyspozycyjnym według następujących równań ${ }^{22}$ :

- wariant dyspozycyjny:

$\mathrm{K}_{\mathrm{npn}}+\mathrm{K}_{\mathrm{b}}=\mathrm{K}_{\mathrm{z}}+\mathrm{K}_{\mathrm{nkn}}$

$\mathrm{K}_{\mathrm{b}}=\mathrm{K}_{\mathrm{bn}} \pm \mathrm{K}_{\mathrm{bo}}$

$\mathrm{K}_{\mathrm{z}}=\mathrm{K}_{\mathrm{zn}} \pm \mathrm{K}_{\mathrm{bo}}$

— wariant rozliczeniowy:

$\mathrm{K}_{\mathrm{npn}}+\mathrm{K}_{\mathrm{b}}=\mathrm{K}_{\mathrm{z}}+\mathrm{K}_{\mathrm{nkn}}$

$\mathrm{K}_{\mathrm{z}}=\mathrm{K}_{\mathrm{zn}} \pm \mathrm{K}_{\mathrm{o}}$

gdzie: $\mathrm{K}_{\mathrm{npn}}$ - koszty normatywne produkcji niezakończonej na początek okresu,

$\mathrm{K}_{\mathrm{b}}$ - koszty okresu bieżącego,

$\mathrm{K}_{\mathrm{z}}$ - koszty produkcji zakończonej,

$\mathrm{K}_{\mathrm{nkn}}$ - koszty normatywne produkcji niezakończonej na koniec okresu,

$\mathrm{K}_{\mathrm{bn}}$ - koszty normatywne bieżącego okresu (według dokumentacji normatywnej),

$\mathrm{K}_{\mathrm{bo}}$ - odchylenia od kosztów normatywnych bieżącego okresu (udokumentowane, nieudokumentowane, nierozpoznane),

$\mathrm{K}_{\mathrm{zn}}$ - koszty normatywne produkcji zakończonej (ustalone na podstawie jednostkowego kosztu normatywnego),

$\mathrm{K}_{\mathrm{o}}$ - odchylenia od kosztów normatywnych bieżącego okresu (nieudokumentowane, nierozpoznane).

$\mathrm{Z}$ jednej strony rachunek kosztów opracowany przez W. Malca był niezwykle rozbudowany i bardzo trudny we wdrożeniu. $Z$ drugiej zaś dzięki informacjom generowanym przez aprioryczny rachunek kosztów pozwalał na ocenę poziomu ponoszonych koszów w wielu przekrojach: dla jednostki półfabrykatu, detalu, wyrobu, braku, fazy produkcji, operacji technologicznej, zespołu pracowników, grupy kosztów, wydziału, maszyny, w relacji do jednostki produktu, w relacji do ceny sprzedaży.

21 A. Jarugowa, W. Malc, K. Sawicki, Rachunek kosztów, Warszawa 1990, s. 242-244.

22 Ibidem, s. 257-265. 
Centrum Informatyki i Badań Ekonomicznych Hutnictwa opracowało i wdrożyło w stalowniach normatywny rachunek kosztów. Pierwsze wdrożenie nastąpiło w latach 1966-1967 w hucie martenowskiej Bobrek i Zygmunt. Ośrodek opracował również zasady stosowania normatywnego rachunku kosztów z wykorzystaniem maszyn cyfrowych. Podkreślono, że zastosowanie maszyn obliczeniowych pozwala uzyskać informacje o kosztach produkcji stali dużo szybciej niż dotychczas (po zakończeniu produkcji, a nie dopiero po miesiącu) i z podziałem na dodatkowe ośrodki odpowiedzialności — brygady. Opracowano również koncepcję obliczania opłacalności asortymentowej wyrobów hutniczych. Wdrożono ją pilotażowo w Hucie Kościuszko. W 1984 roku w Hucie Łabędy wdrożono system operatywnego obliczania kosztów na potrzeby zarządzania oraz sterowania produkcją $\operatorname{stali}^{23}$.

\section{Podsumowanie}

Syntetyczne przedstawienie poglądów wybranych ekonomistów z czasów PRL w układzie chronologicznym wskazuje na ich ewolucję. $Z$ końcem gospodarki socjalistycznej pisano już o maksymalizacji zysków i rentowności przedsiębiorstw pozostających na wewnątrzzakładowym rozrachunku gospodarczym, o efektywności ich działalności i samodzielności finansowej.

Rachunek kosztów jako nieodłączny element wewnątrzzakładowego rozrachunku gospodarczego miał być, zgodnie z założeniem, głównym źródłem informacji dla kontroli realizacji planów produkcyjnych, oceny ich realizacji. Po zakończeniu II wojny światowej rachunek kosztów rozwijał się w Polsce częściowo jako element wewnątrzzakładowego rozrachunku gospodarczego, a częściowo niezależnie. Model apriorycznego rachunku kosztów opracowany teoretycznie przez W. Malca i wdrażany w polskich hutach dostarczał wieloprzekrojowych informacji o kosztach w formie umożliwiającej bezpośrednią kontrolę produkcji, szczegółową ocenę wydajności, racjonalności i efektywności produkcji, produktów, pracowników, urządzeń, materiałów i innych elementów procesu produkcji.

Można więc stwierdzić, że wewnątrzzakładowy rozrachunek gospodarczy, którego immanentną częścią był rachunek kosztów, miał cechy rachunku efektywności. Prowadził więc do dysonansu pomiędzy potencjałem informacyjnym apriorycznego rachunku kosztów a potrzebami gospodarki planowo-rozdzielczej. Jest przykładem nowoczesnych rozwiązań, które były niezbędne w państwie totalitarnym do osiągnięcia pożądanego stopnia kontroli nad społeczeństwem.

23 J. Piga, 30-lecie działalności i dorobek Centrum Informatyki i Badań Ekonomicznych Hutnictwa w latach 1955-1985, s. 42-44, https://www.historiainformatyki.pl/historia/dokument. php?nonav=1\&\&nr ar=8\&nr zesp=9\&sygn=VIII/6/4\&handle=600 (dostęp: 1.11 .2021$)$. 


\section{Bibliografia}

Diaczenko W., Obiektywne podstawy rozrachunku gospodarczego, „Finanse” 1956, nr 4.

Fedorowicz Z., O prawie wartości i rozrachunku gospodarczym, Warszawa 1957.

Jarugowa. A., Malc W., Sawicki S., Rachunek kosztów, Warszawa 1990.

Kronrod J., Podstawy rozrachunku gospodarczego, przeł. B. Wścieklica, Warszawa 1954.

Lange O., Ekonomia polityczna, t 1. Zagadnienia ogólne, Warszawa 1959.

Mitura Z., W kwestii pojęcia rozrachunku gospodarczego, „Annales Universitatis Mariae Curie-Skłodowska. Sectio H. Oeconomia” 1988, nr 22.

Mujżel J., Stosunki towarowe w gospodarce socjalistycznej, Warszawa 1963.

Nowak E., Zarzadzanie kosztami z perspektywy historycznej. Początki koncepcji w ośrodku wrocławskim, „Zeszyty Naukowe Politechniki Częstochowskiej. Zarządzanie” 2018, nr 30.

Piga J., 30-lecie działalności $i$ dorobek Centrum Informatyki i Badań Ekonomicznych Hutnictwa w latach 1955-1985, https://www.historiainformatyki.pl/historia/dokument.php?nona$\mathrm{v}=1 \& \& \mathrm{nr}$ ar= $=8$ nr zesp=9\&sygn=VIII/6/4\&handle $=600$.

Sheremiyet A.D., Goli K., Tioriya i praktika istisleniya sebestoimosti v SSR i KDR, Moskva 1977.

Sochacka R., Rachunkowość w warunkach rozrachunku gospodarczego, praca doktorska, Łódź 1985.

Sochacka R., Rozrachunek wewnątrzzakładowy a rachunek kosztów w ZSRR, „Acta Universitatis Lodziensis. Folia Oeconomica" 1984, nr 41.

Uchwała Rady Ministrów z 17 kwietnia 1950 roku w sprawie zasad organizacji finansowej i systemu finansowego przedsiębiorstw państwowych objętych budżetem centralnym (M.P. z 1950 r. Nr A-55, poz. 630).

Wierzbicki J., Podstawy samodzielności gospodarczej przedsiębiorstw państwowych, „Ruch Prawniczy i Ekonomiczny" 1958, nr 3.

Wiszniewski J., Prawo gospodarcze, Warszawa 1982. 